\title{
Intra-atrial embolus trapped in patent foramen ovale before systemic embolization
}

\author{
Oon Cheong Ooi, FRCS, ${ }^{\mathrm{a}}$ Felix Woitek, MS, ${ }^{\mathrm{d}}$ Raymond Ching Chiew Wong, MRCP, ${ }^{\mathrm{c}}$ \\ Chuen Neng Lee, FRCS, a,b Uwe Klima, MD, PhD, ${ }^{\mathrm{a}, \mathrm{b}}$ and Theo Kofidis, MD, PhD, ${ }^{\mathrm{a}, \mathrm{b}}$ Singapore and Leipzig, \\ Germany
}

We present a case of an embolus traversing the patent foramen ovale (PFO) diagnosed on echocardiography with extensive bilateral pulmonary embolism demonstrated on subsequent computed tomography scan.

\section{CLINICAL SUMMARY}

A 67-year-old woman presented to the emergency department with a subacute onset of exertional dyspnea that was not associated with angina. Her medical history was positive for hypertension and dyslipidemia. Vital signs were stable except for pulse oxymetry of $89 \%$ on room air. Physical examination was positive for mild tachypnea, tachycardia, and a faint systolic murmur. Cardiac enzymes were normal. A subacute valvular pathology was suspected, and an urgent transthoracic echocardiography was performed, which demonstrated an embolus extending from the right atrium to the left atrium across a PFO (Figure 1). The embolus also protruded into the ventricles. In addition, pulmonary hypertension of $70 \mathrm{~mm} \mathrm{Hg}$ systolic pressure was noted. A computed tomography pulmonary angiography was thus obtained to assess the pulmonary arterial tree for possible embolism, revealing the extension of the embolus from the right atrium into the left atrium (Figure 2, $A$ ) and bilateral pulmonary emboli (Figure 2, B).

The patient underwent emergency surgical embolectomy under cardiopulmonary bypass. A 12-cm-long transseptal intraatrial embolus traversing the PFO and floating freely into the ventricles and an extensive bilateral pulmonary embolism were found intraoperatively. Both the emboli in the atria and the main pulmonary arteries were removed via a right atriotomy and pulmonary arteriotomy, respectively, and the PFO was closed with primary suturing. The patient made a good postoperative recovery. Postoperative Doppler ultrasound of the lower limbs revealed deep venous thrombosis in the right thigh, most likely the origin of the thrombus.

\footnotetext{
From the Department of Cardiac, Thoracic and Vascular Surgery, ${ }^{\mathrm{a}}$ The Heart Institute-National University Hospital, Singapore; Department of Surgery, ${ }^{\mathrm{b}}$ Yong Loo Ling School of Medicine, National University of Singapore, Singapore; Cardiac Department, ${ }^{\mathrm{c}}$ The Heart Institute-National University Hospital, Singapore; and University of Leipzig-Heart Center, ${ }^{\mathrm{d}}$ Leipzig, Germany.

Disclosures: None.

Received for publication June 11, 2008; accepted for publication July 4, 2008; available ahead of print March 27, 2009.

Address for reprints: Theo Kofidis, MD, PhD, Department of Cardiac, Thoracic and Vascular Surgery, The Heart Institute, National University Hospital, 5 Lower Kent Ridge Road, Singapore 119074

J Thorac Cardiovasc Surg 2010;139:e49-50

$0022-5223 / \$ 36.00$

Copyright (c) 2010 by The American Association for Thoracic Surgery

doi:10.1016/j.jtcvs.2008.07.064
}

\section{CONCLUSIONS}

In this patient, the embolus was trapped by the PFO and discovered before systemic, including cerebral, embolism. Patients with subtotal occlusion of the pulmonary arterial tree may tolerate this condition well, and subtle manifestation of symptoms can lead to a delayed or wrong diagnosis. Echocardiography was the first-line diagnostic tool for ruling out valvular heart disease. This modality can help to determine right heart tension, pulmonary pressure, and cardiac function in case of pulmonary emboli, which are important markers for choosing the right treatment option. In the presented case, we detected a PFO as a severe condition with deep venous thrombosis, and systemic embolization was prevented. It is prudent to perform a first-line computed tomography pulmonary angiogram to assess for the presence of pulmonary embolism. The intracardiac condition as possible thrombi, impairment of heart and valvular function, and septal defects of the heart should be assessed with additional echocardiography. Both modalities can image a wide variety of causes for dyspnea, decreased oxygen saturation, and a new cardiac murmur. The question of the best first-line strategy remains controversial. This decision will depend on the presentation of the patient, accessibility of the modality, and preference of the performing physician.

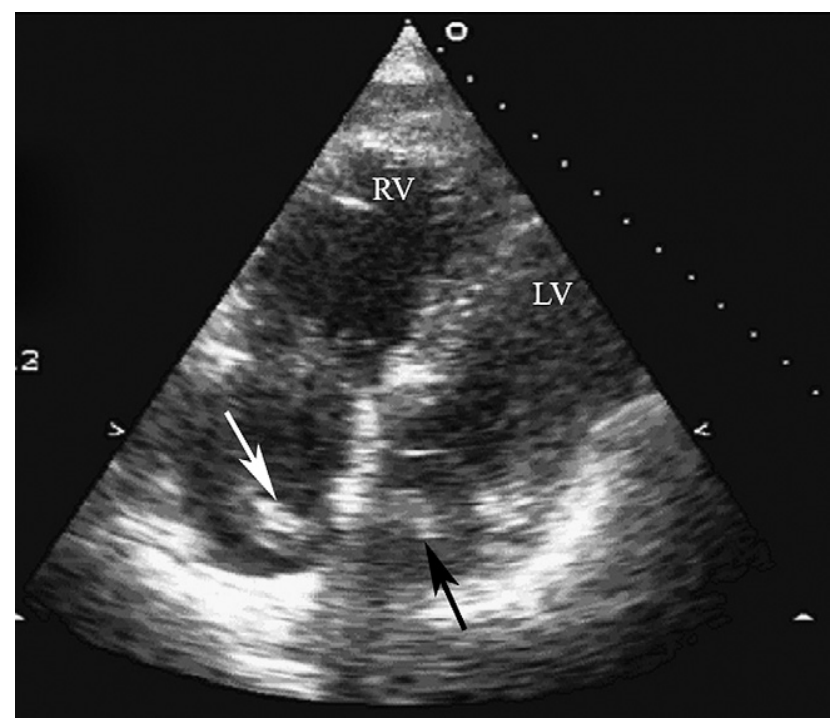

FIGURE 1. Modified apical 4-chamber view during 2-dimensional echocardiography showing elongated embolus (arrows) in transit from the right atrium (white arrow) to the left atrium (black arrow) through the PFO. $R V$, Right ventricle; $L V$, left ventricle. 

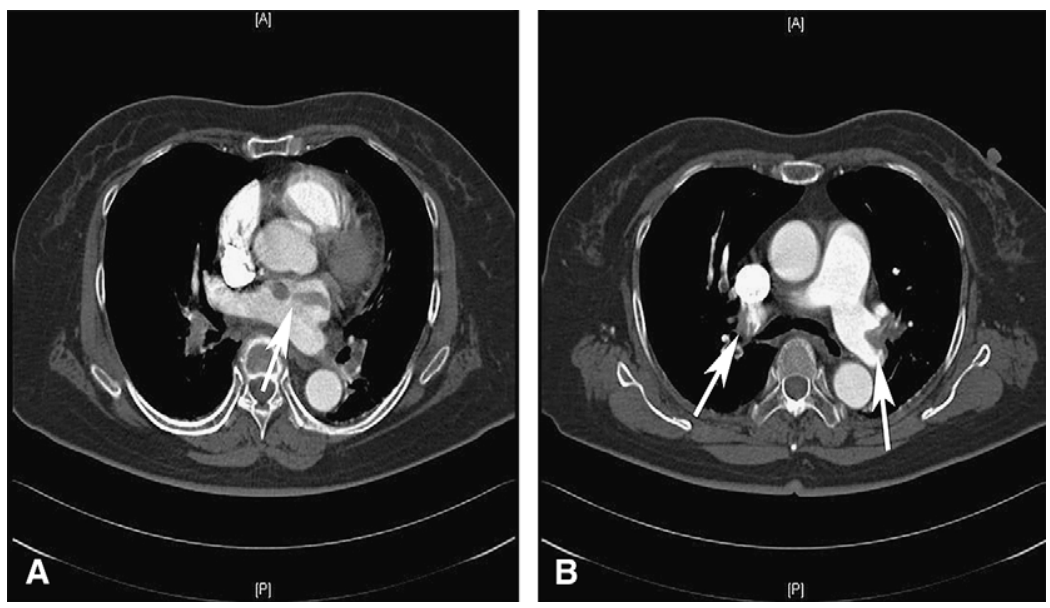

FIGURE 2. Computed tomography scan showing extension of embolus into the left atrium (A, arrow). Contrast-enhanced computed tomography scan showing the emboli (arrows) in the distal left and right main pulmonary arteries (B).

\title{
Lung transplantation for pulmonary alveolar microlithiasis
}

\author{
Norihisa Shigemura, MD, Christian Bermudez, MD, Brack G. Hattler, MD, Bruce Johnson, MD, \\ Maria Crespo, MD, Joseph Pilewski, MD, and Yoshiya Toyoda, MD, Pittsburgh, Pa
}

Since the first description of pulmonary alveolar microlithiasis (PAM) by Puhr ${ }^{1}$ in 1933, nearly 500 related cases have been reported worldwide. No effective treatment for PAM currently exists, with the exception of lung transplantation. Herein, we present the case of a 63-year-old woman with PAM who, to the best of our knowledge, is the oldest successful lung transplant recipient with end-stage PAM reported. In addition, the present work reviews the outcomes of other cases of PAM after lung transplantation.

\footnotetext{
From Cardiopulmonary Transplantation, University of Pittsburgh Medical Center, Pittsburgh, Pa.

Disclosures: None.

Received for publication May 27, 2008; accepted for publication July 5, 2008; available ahead of print Feb 23, 2009.

Address for reprints: Norihisa Shigemura, MD, Osaka University Graduate School of Medicine, Department of Thoracic Surgery, L5, 2-2 Yamada-oka, Suita, Suita, Osaka, 565-0871 Japan (E-mail: shigemura@thoracic.med.osaka-u.ac.jp).

J Thorac Cardiovasc Surg 2010;139:e50-2

$0022-5223 / \$ 36.00$

Copyright (c) 2010 by The American Association for Thoracic Surgery doi:10.1016/j.jtcvs.2008.07.066
}

\section{CLINICAL SUMMARY}

A 63-year-old woman with PAM was initially referred to our clinic for evaluation in 1998. The diagnosis was based on results of an open lung biopsy performed 16 years earlier, and the disease showed gradual progression, with 5 spontaneous instances of pneumothorax. The patient eventually became dependent on supplemental oxygen and was markedly limited in activities of daily living (from Fletcher Hugh-Jones criteria 4 to 5). She was deemed to be a suitable candidate for lung transplantation on the basis of our multidisciplinary transplant selection committee criteria. At the time of listing, she had moderately restricted pulmonary function with a forced vital capacity of $1.65 \mathrm{~L}$ (50\% of predicted), a forced expiratory volume in 1 second of $1.49 \mathrm{~L}(62 \%$ of predicted), and a diffuse capacity for carbon monoxide of $4.05 \mathrm{~L} \cdot \mathrm{min}^{-1} \cdot \mathrm{kPa}^{-1}(17 \%$ of predicted). Her 6-minute walk result was 830 feet on $5 \mathrm{~L}$ of oxygen provided via a nasal cannula with desaturation to $79 \%$. Cardiac catheterization showed a systolic pulmonary artery pressure of $47 \mathrm{~mm} \mathrm{Hg}$, a transpulmonary gradient of $22 \mathrm{~mm} \mathrm{Hg}$, and mild coronary artery disease. A chest radiograph and computed tomographic scan on admission are shown in Figure 1. 